\title{
A Countercultural Heritage: Rediscovering the Relationship-Centered and Social Justice Roots of Family Medicine-A Perspective from the Keystone IV Conference
}

\author{
Richard C. Waters, MD, MSc, Mark Stoltenberg, MD, MA, \\ and Lauren S. Hughes, MD, MPH, MSc, FAAFP
}

The 2015 G. Gayle Stephens Keystone conference convened a cohort of primary care professionals to discuss what promises personal physicians will make to their patients going forward. New physicians were prompted to rediscover the foundational values of and historic context for family medicine. At the heart of this rediscovery was learning of the writings and teachings of Dr. G. Gayle Stephens, a founder of family medicine who emphasized the essentiality of relationship-centered care and social justice to the new specialty. Dr. Stephens viewed family medicine as being in a countercultural relationship to mainstream medicine, as family medicine fought for justice and equity in an inequitable and fragmented health care system. Here we argue that by reaffirming and renewing this countercultural heritage the new generation of family physicians will have better clarity in approaching the many challenges in health care today. Particularly for trainees and new physicians, the historic lens offered by Dr. Stephens's writing and other foundational documents allows us to better see ourselves in a trajectory of ongoing health care reform. (J Am Board Fam Med 2016;29:S45-S48.)

Guest editors' note: This article was prepared after the G. Gayle Stephens Keystone IV Conference by authors from the youngest generation of conference attendees. It exposes some of the impact of the conference, an enduring interest by young physicians in being a personal physician, and an inspiring commitment by early career physicians to reimagining the personal physician going forward.

Keywords: Doctoring, Family Medicine, Family Physician, Health Care Delivery, Personal Physician, Population Health, Primary care, Professionalism, Social Justice

For those of us recently joining the ranks of family physicians, it has not always been easy to describe or even recognize exactly what led us into the specialty. Some of us felt compelled by the chance

This article was externally peer reviewed.

Submitted 4 January 2016; revised 31 March 2016; accepted 18 April 2016.

From Neighborcare Health, Seattle, WA (RCW); the Harvard Interprofessional Palliative Care Fellowship Program, Harvard Medical School, Cambridge, MA (MS); and the Pennsylvania Department of Health, Harrisburg (LSH).

Funding: none.

Conflict of interest: none declared.

Corresponding author: Richard C. Waters, MD, MSc, Neighborcare Health, 1200 12th Avenue S, Suite \#901, Seattle, WA 98144 (E-mail: rcwaters@gmail.com). to care for patients over decades and even generations. Others were inspired by a mentor who continually fought for a better tomorrow for their patients and the communities in which they live. But despite our own personal explanations and experiences, we have always felt that something profound rests at the core of our specialty.

After attending the G. Gayle Stephens Keystone conference, ${ }^{1}$ the essence of what makes family medicine so special became abundantly more clear for those of us belonging to the newest generation of family physicians. At the heart of this revelation was the legacy of the man to whom the conference was dedicated-Dr. Gayle Stephens. Dr. Ste- 
phens's influence was seen not only in the conference title but also in allusions by multiple speakers and in the conference readings. Intrigued, we delved deeper to learn more about this family medicine founder.

Dr. Stephens clearly delineated that at the core of family medicine is its unwavering commitment to individual patients as opposed to specific diseases, organs, or technologies. ${ }^{2} \mathrm{He}$ envisioned a specialty in which physicians followed their commitment to the whole patient beyond the examination room and into the public sphere, as advocates for social justice. His vision of using social justice as our map and relationships as our compass was essential to the development of our specialty and the evolution of American medicine as it is today. ${ }^{3,4}$ For us young physicians, his words and the historic context of the founding of family medicine brought clarity to our decisions to become family physicians.

At the same time, we feel disappointed as we work in a health care system that seems to be anything but patient-centered. ${ }^{5}$ Relatively limited funding for primary care, increased clerical demands, and limited resources for care coordination, all within the context of an aging population, have incentivized shorter visits and illness-focused, fragmented care. These trends threaten the characteristics of care considered important by patients and care teams alike-in particular the accessibility, continuity, and coordination of care.

With these problems in mind, we were grateful to bear witness to how the values exemplified at Keystone inspired a generation of family medicine leaders before us. We argue that by reaffirming and renewing our specialty's core originating tenetsrelationship-focused care and social justice-we, the new generation of family physicians, will have better clarity in approaching the many challenges in health care today.

\section{Rediscovery}

Dr. Stephens's words brought both life and clarity to the subtle yet undeniable calling we physicians in our early careers have all instinctively felt toward family medicine. Much like the field's founders during the social upheaval of the 1960s and 1970s, the path to family medicine for many in our generation was paved by values that reflect the events and social movements of our time. In a world more connected and more mobile than ever before, our generation has given strength to movements for fair working conditions here and abroad, for the respect of and access to medicines for people living with HIV/AIDS, for the support of health infrastructures in communities most in need, for equal rights for LGBTQ persons, for \#BlackLivesMatter, and more. We have been raised in a society still visibly grappling with questions of justice and equity-all with consequences for the health of communities. What better specialty to tackle such questions than one with community roots.

But we hadn't heard during our years of training that family medicine itself was rooted in reform, with a legitimate obligatory interest in transforming the system on behalf of patients. ${ }^{6} \mathrm{We}$ were not told that the founders viewed the discipline as "standing in a countercultural relationship to mainstream medicine," 3 an adversarial bond highlighting that this new discipline was not to be a foundation to support the fragmented health care system, but the infrastructure on which to build a new, relationship-centered one. It was never made explicit to us that family medicine did not become the champion of relationships and of social justice by accident; these values were intentionally ingrained by the leaders of our specialty from its very inception.

Realizing concordance between our presentday values and those held as foundational at the birth of our specialty was both validating and energizing. Before, we had only sensed that family medicine could be more than clinical training to care for patients of all ages. Now, we know that our intuition was right: This specialty is part of a broader social movement, countercultural in its adamancy for change. We maintain this assertion that "countercultural" remains an apt description of family medicine today, since, judging by the chorus for change heard at the Keystone conference and our other collective experiences, we remain a specialty pushing against the status quo, working to disrupt a fragmented, paymentcentric system in favor of a patient-centered, relationship-oriented system. Hearing stories at Keystone of how the current generation of family medicine leaders has preserved this heritage of justice, we left with a deep sense of gratitude for their work. Discovering the historic values of family medicine_-and of Dr. Stephens himself- 
has given meaning to our daily work. We wish we had reached this discovery sooner.

\section{Reaffirmation}

As our generation carries this impressive legacy forward, we hope that family medicine's heritage and Dr. Stephens's writings will be reaffirmed for ourselves and for future medical trainees. What we heard at the Keystone conference illustrated that publicly vocalizing shared values is essential in sustaining momentum for change. We were inspired to witness how the process of expressing our shared values together brought about new energy and excitement, even for the most experienced clinicians at the conference.

We view these values as more than lofty rhetoric. As physicians who appreciate an emphasis on evidence-based medicine and evidence-based policy, any affirmation should be supported by data. Since the Whitehall studies, the evidence base for the importance of social determinants of health and interventions to address them has grown quickly. ${ }^{7-11}$ The available evidence on the impact of physicianpatient relationships is more limited, but what does exist points to a positive impact. ${ }^{12}$ Furthermore, innovative models emphasizing relationships in primary care are promising. ${ }^{13,14}$

Our reaffirmation of the values central to family medicine takes several forms. We will openly embrace our countercultural heritage, even as we strive to create a more equitable system for health and thus strive to become mainstream through change. We will take pride that it is not just the individuals in family medicine who value social and economic justice in addition to clinical excellence, but the discipline itself. We acknowledge that amid an increasingly technological and mobile society, the legacy of striving for justice through an unceasing commitment to relationships with patients may seem threatened. Yet we remain optimistic of being able to hold true to a promise to keep relationships as the true north of medicine, even if those relationships are redefined in an evolving cultural milieu. Most important, we have realized the importance to trainees of learning about the history of the primary care movement as it relates to its values. We will advocate for the inclusion of such writings as by Dr. Stephens; summaries of the Millis, Willard, and Folsom Reports; and the 1978 declaration of Alma Ata as essential for trainees. As we speak our values loudly and publicly, they will help guide our actions and policies.

\section{Renewal}

With an estimated 32 million individuals in the United States without health insurance, ${ }^{15}$ persistent health disparities, ${ }^{16}$ and an undervalued primary care system, we still find ourselves seeking to transform the health system for the betterment of everyone who ever has or ever will be a patient. That aspiration continues to put us in a countercultural relationship with the status quo. As Dr. Stephens noted, "There is no intrinsic virtue in standing in a countercultural relationship to mainstream medicine, but it is only as the inequities are healed that we can rejoin the mainstream as fullfledged members." ${ }^{3}$ And so we must renew and redouble the efforts aimed at transforming health care begun decades prior. Our values in family medicine must be operationalized. And so, in response to the charge we received at the Keystone conference of how we will "be there" for our patients, we propose the following promises from the perspective as newly minted family doctors.

First and foremost, we will be unwavering in our commitment to relationship, to flatten the power differential between patient and health team, and to be present especially at those critical transitions of care when our patients need us most. We will also remember that our purpose as healers and our commitment to the whole patient includes a call to action outside our clinics. We promise to advocate for relationship-centered care for all as the foundation for a new health care system. Inherent in this goal is working toward universal access to health care, so that those who are currently unable to establish a relationship with a health team can do so. Innovations at the clinic and system levels that enhance accessibility, continuity, and coordination of care will ultimately enhance the strength of patient-care team relationships. We also acknowledge our mandate to bear witness to the powerful impact of the social, economic, and political determinants of health; to persistent institutional racism; and to unique hardships faced by those new to this country.

Family medicine succeeded because Dr. Stephens and his contemporaries identified and integrated with social movements of their time. They realized the essentiality of relationships to both 
quality care and socially responsible care. And while there is already a social movement on multiple fronts aimed at transforming health care today, often with a strong presence of medical trainees and new physicians, we contend that there is great value in our generation's knowing intimately the countercultural heritage of family medicine. This historic lens provides us clearer direction as new family physicians in a rapidly evolving health care ecosystem. We anticipate that no matter how you discover Dr. Stephens, you will find his fundamental ideas and teachings as powerful as we have.

\section{References}

1. Green LA, Puffer JC. Reimagining Our Relationships with Patients: A Perspective from the Keystone IV Conference. J Am Board Fam Med 2016; 29(Suppl 1):S1-S11.

2. Stephens GG. The intellectual basis of family practice. Tucson, AZ: Winter Publishing Company; 1982.

3. Stephens GG. Family medicine as counterculture. Fam Med 1989;21(2).

4. Stephens GG. Remembering 40 years, plus or minus. J Am Board Fam Med 2010;23(Suppl 1):S5-10.

5. Relman A. On breaking one's neck. The New York Review of Books, February 6, 2014. Available from: http://www.nybooks.com/articles/archives/ 2014/feb/06/on-breaking-ones-neck/. Accessed November 22, 2015.

6. Stephens GG. Family practice and social and political change. Fam Med 2001;33:248-51.

7. Marmot MG, Rose G, Shipley M, Hamilton PJ. Employment grade and coronary heart disease in
British civil servants. J Epidemiol Community Health 1978;32:244-9.

8. Braveman P, Egerter S, Williams DR. The social determinants of health: coming of age. Annu Rev Public Health 2011;32:381-98.

9. Koh HK. A 2020 vision for healthy people. N Engl J Med 2010;362:1653-6.

10. World Health Organization. Closing the gap in a generation: health equity through action on the social determinants of Health: Commission on Social Determinants of Health Final Report. Geneva: World Health Organization; 2008.

11. Nelson AR, Smedley BD, Stith AY, eds. Unequal treatment: confronting racial and ethnic disparities in health care. Washington, DC: National Academies Press; 2002.

12. Kelley JM, Kraft-Todd G, Schapira L, Kossowsky J, Riess H. The influence of the patient-clinician relationship on healthcare outcomes: a systematic review and meta-analysis of randomized controlled trials. PLoS One 2014;9:e94207.

13. Fernandopulle R. Restoring humanity to health care. J Ambul Care Manage 2014;37:189-91.

14. Wu WN, Bliss G, Bliss EB, Green LA. Practice profile. A direct primary care medical home: the Qliance experience. Health Aff (Millwood) 2010;29: 959-62.

15. Key facts about the uninsured population. Menlo Park, CA: Kaiser Family Foundation; 2015. Available from: http://kff.org/uninsured/fact-sheet/keyfacts-about-the-uninsured-population/. Accessed October 23, 2015.

16. Agency for Healthcare Research and Quality. National healthcare disparities report. Rockville, MD: US Department of Health and Human Services; 2014. 